\title{
FEEDER RECONFIGURATION AND CAPACITOR PLACEMENT IN DISTRIBUTION SYSTEMS: AN APPROACH FOR SIMULTANEOUS SOLUTION USING A GENETIC ALGORITHM
}

\section{RECONFIGURACIÓN Y UBICACIÓN DE CONDENSADORES EN SISTEMAS DE DISTRIBUCIÓN: METODOLOGÍA DE SOLUCIÓN SIMULTÁNEA USANDO ALGORITMOS GENÉTICOS}

\author{
Horacio Díaz R. ${ }^{1} \quad$ Ildefonso Harnisch V. ${ }^{1} \quad$ Raúl Sanhueza H. $^{1} \quad$ Romina Olivares R. $^{2}$ \\ Recibido 15 de noviembre de 2007, Aceptado 18 de marzo de 2010 \\ Received: November 15, 2007 Accepted: March 18, 2010
}

\begin{abstract}
RESUMEN
Este trabajo presenta una metodología para la solución simultánea de los problemas de ubicación de condensadores y reconfiguración de alimentadores en sistemas eléctricos de distribución radiales, con el fin de mejorar el perfil de voltaje de la red y, al mismo tiempo, reducir los costos asociados a las pérdidas de energía y potencia. Considerando un perfil de carga dado, se propone un método de optimización usando un algoritmo genético para determinar el tamaño óptimo, ubicación, tipo y número de condensadores fijos o conmutables, así como los estados abierto/cerrado de las llaves (switches) seccionadoras y de interconexión. La formulación del problema considera la minimización de los costos totales, incluyendo costos fijos y variables de los bancos de condensadores. El método propuesto se ha probado en diversas redes y los resultados muestran que considerando ambos problemas simultáneamente los costos debidos a las pérdidas se pueden minimizar hasta un 10\% más que tomando dichos problemas por separado. Se presentan los resultados obtenidos en un sistema IEEE de 16 barras y una red de distribución real de 733 barras.
\end{abstract}

Palabras clave: Sistemas de distribución, reconfiguración, ubicación de condensadores, algoritmos genéticos.

\begin{abstract}
This paper presents an effective approach to simultaneous solution of capacitor placement and feeder reconfiguration for power-energy loss cost minimization and voltage profile enhancement in radial distribution systems. Considering a time variation load, an optimization method using a genetic algorithm is proposed to determine the optimal location and size of fixed and switchable capacitors, as well as the open/closed states of the sectionalizing and tie switches. Reduction of overall power and energy losses and capacitor costs are involved in problem formulation. The proposed approach is demonstrated using example systems from the literature and results show that taken into account both capacitor placement and feeder reconfiguration simultaneously can generate around $10 \%$ more energy and peak loss reduction than considering them separately. Simulations results are presented for a 16 bus IEEE system and for a 733 bus practical distribution network.
\end{abstract}

Keywords: Distribution systems, feeder reconfiguration, capacitor setting, genetic algorithms.

\section{INTRODUCTION}

The pressure to improve overall efficiency has forced utilities to seek greater efficiency in distributions systems; communication and computing technology allow remote supervisory and control of capacitor and reconfiguration switches. In turn, this allows cost-effective solutions to loss minimization without any violations of operational conditions (voltage limits, maximum currents, radial configuration).
The problem of loss minimization can be obtained by an optimal setting of capacitors and feeder reconfiguration.

Capacitor setting is the process to determine capacitor types, sizes, locations and control schemes; and is the most widely accepted mean of improving voltage profile, power factor correction and loss reduction in distribution networks, but other operational parameters are also improved, like the peak current flows on network laterals and the total peak MVA of the system.

\footnotetext{
1 Escuela Universitaria de Ingeniería Eléctrica-Electrónica. Universidad de Tarapacá. Arica, Chile. E-mail: hdiaz@ uta.cl; harnisch@uta.cl; sanhueza@uta.cl

2 Codelco, División Codelco Norte. Mina Chuquicamata. Edificio institucional de Codelco Norte. 11 Norte 1291. Villa Exótica. Calama, Chile.

E-mail: roliv22@ codelco.cl
} 
Feeder reconfiguration is the process to determine a radial topological structures of distribution feeder by changing the open /closed states of the sectionalizing and tie switches in order to reduce losses, increase system security and enhance power quality.

The difficulty to solve the presented problems makes them to be resolved in an independent way. For this reason most of the studies handled capacitor setting without considering feeder reconfiguration or handled reconfiguration problems without considering the capacitor addition.

Optimal capacitor setting has been investigated since the 60's, [1-13]. Early approaches were based on heuristic techniques applied to relaxed versions of the problem. In the 80's, Grainger [1] formulated a more rigorous approach based on a no linear programming model solved by gradient search, Baran [2] proposed a solution by Benders decomposition. In the 90's evolutionary computation were proposed as means of solving the capacitor setting problem; Sundhararajan [4] used genetic algorithm (GA) to select capacitor for radial distribution system, Chiang [3] proposed Simulated Annealing (SA), Huang [5] used tabu search, Lai [6] and Lee [7] used evolutionary programming to solve optimal reactive power planning problem. In the 2000's Gallego [9] proposed a hybrid method draw upon the tabu search, extended with features taken from GA and SA.

Feeder reconfiguration has been relatively recently studied, [14-23], due to advanced computing and control capabilities required for its study. One of the first works reported was presented by Merlin and Back [14]. It presents an integer-mixed non-linear optimisation model that is solved through the discrete branch and bound method. Due to the combinatorial nature of the problem, it requires checking a great number of configurations for a real-sized system

In the 80's Civanlar [15] used a heuristic method for the estimation of the loss reduction obtained by a particular switching option (Switch exchange method), Shirmohammadi [16] used other heuristic method based on the switches having the lowest current flow (sequential switch opening method). In the 90's evolutionary computation is also proposed to solving the feeder reconfiguration problem. Nara [17] present an implementation using GA, Cheng [18] used a SA approach and Hsiao [21] used evolutionary programming.

Only a few papers on loss minimization for simultaneous feeder reconfiguration and capacitor setting had been presented, [24-31]. In the 90's, Peponis [19] used a two steps heuristic procedure, one for obtain a feeder reconfiguration and other for determine fixed capacitor size and location, this procedure is repeated until the two steps produce the same configuration and capacitor arrangements; Jiang [24] used a two steps procedure too, the first one employed SA to optimise the switch configuration and the second one a discrete optimisation algorithm to optimal capacitor control. In the 2000's Su and Lee [25] presented a first approach for feeder reconfiguration and capacitor setting simultaneously using SA, but they do not consider energy losses neither capacitors costs; Rong [27] proposed a cross-iteration optimization method, by alternately performing feeder reconfiguration and capacitor control; Dong [29-30] proposed a improved adaptive genetic algorithm to optimizing capacitor switching and a simplified branch exchange for each genetic instance at each iteration of capacitor optimization algorithm. Chang [31] proposed an ant colony search algorithm (ACSA) showed that the performance of the ACSA method is better than those obtained by the SA and GA, but the approach only considering fixed capacitors.

This paper presents a genetic algorithm for optimal loss minimization of distribution systems under jointly optimal capacitor setting and feeder reconfiguration. The proposed methodology has the following characteristics:

- It solves a multi-objective optimization problem for capacitor setting and feeder reconfiguration simultaneously, considering operating and engineering constraints.

- It is applicable to large-scale distribution systems with comprehensive modelling of diverse distribution components; including loads represented by diverse voltage dependent models, fixed and switchable capacitors, sectionalizing and tie switches, transformer losses.

- It considers power losses and capacitors costs.

- It considers a non-iterative power flow method for losses estimation.

- It attains a higher quality solution than classical methods for loss reduction in distribution systems.

\section{PROBLEM FORMULATION}

Given a balanced radial distribution network with a known topological structure, the problem consists on finding, for each load level, an optimal capacitor setting and a radial network among all possible radial networks generated with the switch condition changes (reconfiguration) and all possible capacitors types considered (capacitor placement), that minimizes the power and energy losses and that does not infringe the networks load flows and 
operational constraints. This is a combinatorial, non differentiable and a mixed integer non-linear optimization problem.

The simultaneous solution of the optimal reconfiguration and capacitor setting problem determines which network switches should be open and which closed as well as capacitor types, sizes, control and locations in order to reduce losses, to improve voltage profile and, in a more limited way, to increase feeder capacity, under different load curves conditions and satisfying equipment and operation constraints.

In this paper the objective function is formulated as minimization of costs and investments $(C)$ over a time period $\mathrm{T}$, including power losses and energy losses, then the objective is to reduce the energy losses and peak power losses (PPmax) on the system while striving to minimize the cost of capacitor in the system $\left(\mathrm{C}_{\mathrm{c}}\right)$. The cost of a switch state condition change is not considered. The mathematical formulation is described in equation (1).

$$
\min C=C E_{p}(T)+C P_{p}(T)+C_{C}
$$

Subject to:

$$
\begin{array}{ll}
V_{\min } \leq V_{i}(t) \leq V_{\max } & i=1,2, \ldots n, 0<t<T \\
I_{j}(t) \leq I_{\max _{j}} & j=1,2, \ldots(n-1), 0<t<T \\
Q_{C_{k}}(t) \leq Q_{C_{\max }} & k=1,2, \ldots . N_{\text {cond }}, 0<t<T \\
Q_{C_{k}}(t)=Q_{C d i s p_{m}} & m=1 ; 2, \ldots . N c_{\text {disp }} \\
N_{\text {cond }} \leq n c &
\end{array}
$$

No feeder section can be left out of service and radial network structure must be retained.

Where:

$\mathrm{V}_{\min }, \mathrm{V}_{\max }$ : Upper and lower limit for bus voltage

$\mathrm{Ij}_{\mathrm{j}}, \operatorname{Imax} \mathrm{j} \quad$ : Current magnitude of branch $\mathrm{j}$ and upper limit

QCk,QCmax k : k-th capacitor reactive power and upper limit

QCdisp m : m-th available level of capacitor reactive power

n : The total number of buses

Ncond : The Number of new capacitors

NCdisp : The Number of available level for new capacitors

Nc : Upper limit for new capacitors
The energy $\left(\mathrm{CE}_{\mathrm{p}}\right)$ and active power losses $\left(\mathrm{CP}_{\mathrm{p}}\right)$ costs associated to a particular network configuration are evaluated with the equation (2), (3), where $\mathrm{Ke}$ is the energy cost factor and $\mathrm{Kp}$ is the active power cost factor. To calculate the energy losses in the system, the load variations for a given period of time $\mathrm{T}$ are taken into account considering the load profile, using the load duration curve, Figure 1.

A set of simplified feeder-line flow formulations called "Simplified Power Summation Method" is employed to avoid complex power flow computation [20].

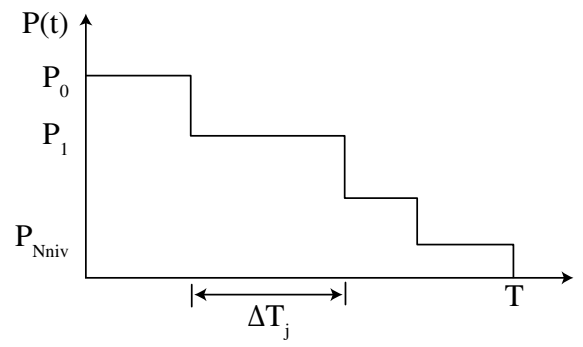

Figure 1. Discrete load duration curve.

$$
\begin{gathered}
C E_{p}(T)=K e \sum_{j=1}^{N n i v} P_{p}(j) \cdot \Delta T_{j} \\
C P_{p}(T)=K p \cdot P p_{\max }
\end{gathered}
$$

The formulation considers fixes $\left(\mathrm{Q}_{\mathrm{CF}}\right)$ and switches $\left(\mathrm{Q}_{\mathrm{CV}}\right)$ capacitors with a cost function such as Figure 2 shows.

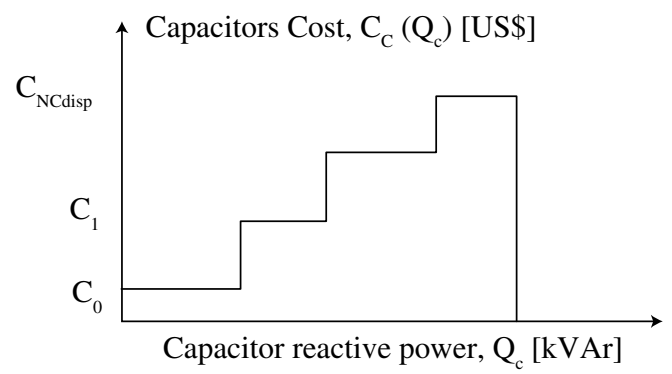

Figure 2. Capacitors cost function.

From Figure 2, the total cost for new capacitor allocation $\left(\mathrm{C}_{\mathrm{c}}\right)$ is given by equation (4).

$$
C_{C}=\sum_{i=1}^{n c v} C\left(Q_{C V i}\right)+\sum_{i=1}^{n c f} C\left(Q_{C F i}\right)
$$




\section{GENETIC ALGORITHM}

To solve the optimization problem formulated in equation (1) a genetic algorithm (GA) is proposed, the most popular form of Evolutionary Algorithms, inspired by the principle of evolution and, in essence, consists on a population of strings transformed by three genetic operators: selection, crossover and mutation. Each string (chromosome) represents a possible solution to the problem being optimized and each part of the string (sub string) represents a value for some variable of the problem (gene). These solutions are classified by an evaluation function, giving better values, or fitness, to better solutions. Each solution must be evaluated by the fitness function (having the role of environment) to produce a value. The pair (chromosome, fitness) represents an individual. The GA algorithm proposed in this paper has the following characteristics, [26].

\section{Coding}

Each possible radial distribution system with some switches states and capacitor setting is an individual in the population represented by a four sub string such as Table 1 shows.

Table 1. Coding for the feeder reconfiguration and capacitor setting problem.

\begin{tabular}{|c|c|l|}
\hline Sub string & Coding & \multicolumn{1}{|c|}{ Interpretation } \\
\hline $\begin{array}{c}\text { Capacitor } \\
\text { reactive } \\
\text { power }(\mathrm{Qc})\end{array}$ & Integer & $\begin{array}{l}\text { Vector with elements that } \\
\text { designate the Qc for each } \\
\text { load level. }\end{array}$ \\
\hline $\begin{array}{c}\text { Capacitor } \\
\text { allocation }\end{array}$ & Integer & $\begin{array}{l}\text { Vector with elements that } \\
\text { designate the bus number for } \\
\text { the capacitor placement. }\end{array}$ \\
\hline $\begin{array}{c}\text { Switches } \\
\text { states }\end{array}$ & Binary & $\begin{array}{l}\text { Vectors with the switches } \\
\text { states for each load level }\end{array}$ \\
\hline $\begin{array}{c}\text { Network } \\
\text { configuration }\end{array}$ & Integer & $\begin{array}{l}\text { Predecessor vectors that } \\
\text { designate the network topologic } \\
\text { for each load level. }\end{array}$ \\
\hline
\end{tabular}

The sub string is as follows:

An integer code to the reactive power, considering fixed and switched capacitor for each load level.

An Integer code to designate the bus capacitor location.

A binary code to the switches states for each load level. If the binary value is zero the switch is open and it is one the switch is closed.
An integer code to the topological system configuration for each load label based on a predecessor vector [26]; this representation indicates for each node its predecessor, in other words, the nearer node from which receives the feeding.

\section{Initialization}

A random initial population is considered. Parameters of GA must be initialized such as generation size, population size, crossover probability and mutation probability for capacitor addition and feeder reconfiguration.

\section{Fitness Evaluation}

All individual are evaluated with the same fitness function. The fitness function incorporates the objective function, i.e., the total costs associated to power losses, energy losses and capacitors equation (1) with cost penalties if a individual violates any of the constraints. The fitness function, $\mathrm{fk}$, can be expressed as follows:

$$
f_{k}=C_{k}+\alpha \cdot \Delta V_{k}+\beta \cdot \Delta I_{k}
$$

Where:

$\mathrm{C}_{\mathrm{k}}$ : Total cost of individual $\mathrm{k}$ (equation 1)

$\alpha \quad$ : Voltage penalty factor

$\beta \quad$ : Current penalty factor

$\Delta \mathrm{V}_{\mathrm{k}}$ : Voltage constraints

$\Delta \mathrm{I}_{\mathrm{k}}$ : Currents constraints

A significant value (over 10000) is given to $\alpha, \beta$ penalty factors if the associated voltage or current constraint is violated, this makes the objective function more away from the undesirable solution.

\section{Reproduction operation}

In this operation, the matting pool needs to be formed by the population in proportion to their elitism. Elite ones will copy more to the matting pool. The roulette wheel selection was used to guarantee the occupancy of an area equal to the individual's share of the total fitness.

\section{Crossover}

Given a switched and capacitor crossover probability, a crossover is performed considering one or more crossover point.

\section{Mutation}

Given a switched and capacitor crossover probability, random alteration of genes in an individual may occur. A switches mutation represents a simple bit change; a capacitor mutation represents a change in bus number to any valid location or the reactive power setting. 


\section{TEST RESULTS}

The proposed method was implemented in the $\mathrm{C}$ programming language on a Pentium III $550 \mathrm{MHz}$, to demonstrate its performance two system benchmarks was considered for this paper: first a 16 bus IEEE system used to validate the proposed GA methodology with other references [25] and a 733 bus practical distribution system used to test the algorithm efficiency on a practical distribution network [26].

\section{6 bus IEEE test system}

This is a frequently studied IEEE distribution system obtained from [15] and displayed in Figure 3. The system consists of 16 buses, three feeders, 13 sectionalizing switches and three tie switches. This system is used in this paper with two purposes, in the first place to validate the proposed method and in second place to show the advantage of the proposed GA method.

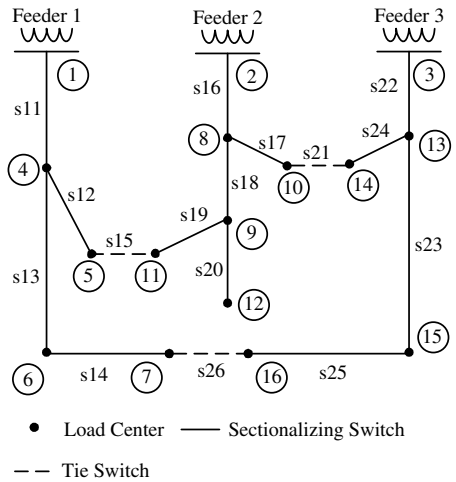

Initial configuration

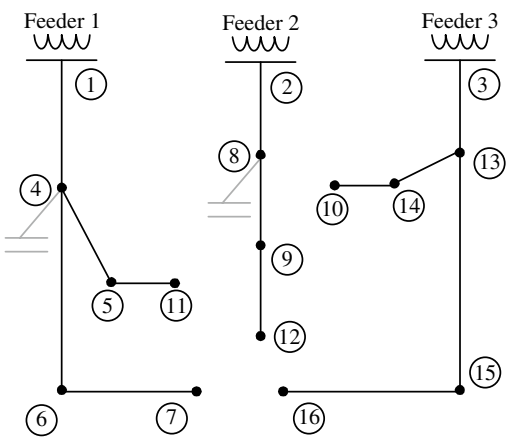

Case c) final configuration. first capacitor addition and then reconfiguration
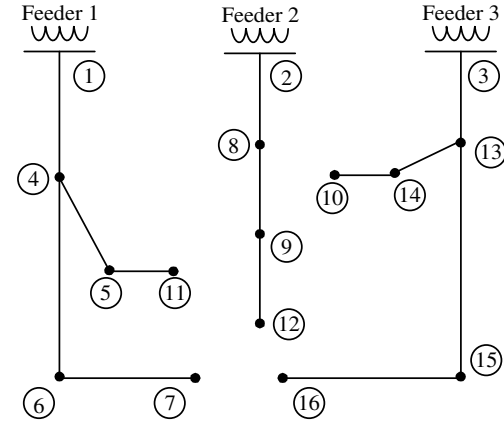

Case a) final configuration, only feeder reconfiguration

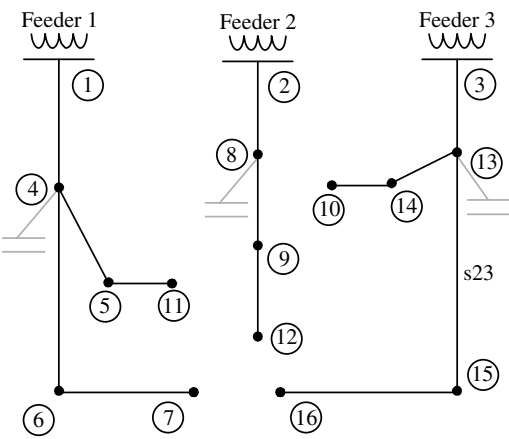

Case d) final configuration. both capacitor addition and reconfiguration simultaneously

Figure 3. Final system configurations for the 16 bus IEEE system, case 1 .

\section{Case 1}

Simulation results are presented for the 16 bus IEEE system and compared to the feeder reconfiguration and capacitor setting obtained from [25], which use simulated annealing (SA) to solve the problem, both feeder reconfiguration and setting of capacitor are taken into account together, but only power losses reduction is considered.
The system load is assumed to be constant and buses 4,8 and 13 are selected to set up capacitor banks for feeder 1, 2 and 3, respectively. Practical size available for the capacitor banks are 300, 600, 900, 1200, 1500 and $1800 \mathrm{kVAr}$. In order to compare results, this paper has considered the same four cases presented by $\mathrm{Su}$ [25]. These four cases are the following: 
Case a: Only feeder reconfiguration is considered.

Case b: Only capacitor addition is considered.

Case c: Both capacitor addition and feeder reconfiguration are considered; however, capacitor addition is carried out before feeder reconfiguration.

Case d: Both capacitor addition and feeder reconfiguration are considering and are taken into account simultaneously.

The genetic parameters setting considered for all simulation cases are show in Table 2, the initial population is randomly determined according to the system size and crossover rate according to typical value for GA algorithm.

The final system configuration for the four cases studied are depicted in Figure 3 and summarized in Table 3.

Taken into account both capacitor setting and feeder reconfiguration simultaneously can generate more power losses reduction than considering them separately, such as Figure 4 shows.

Table 2. Genetic parameters setting. Case 1.

\begin{tabular}{|l|c|}
\hline Genetic Parameter & Setting \\
\hline Initial population size & 100 \\
\hline Preserved population size & 50 \\
\hline Switches mutation rate [\%] & 0.01 \\
\hline Capacitor mutation rate [\%] & 0.01 \\
\hline Crossover rate [\%] & 20 \\
\hline Crossover point rate for capacitor [\%] & 35 \\
\hline Crossover point rate for switches [\%] & 7 \\
\hline
\end{tabular}

Total Power Loss $[\mathrm{kW}]$

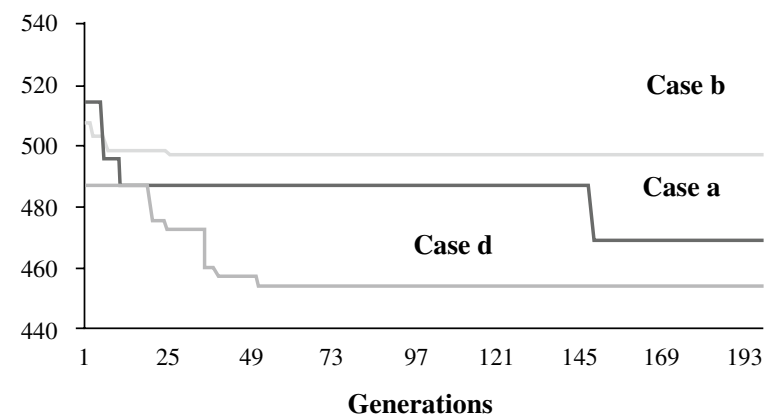

Figure 4. Genetic algorithm performance for the case 1.

The obtained results are the same as [25] presents and validate the proposed methodology. Table 3 show that case d) can reduce power loss the most among these four cases.

\section{Case 2}

It is important to point out that the approaches proposed in this paper minimize the total costs, considering active power and energy losses, and fixed or switched capacitor placement. However, the reference [25] only minimizes active power losses with only fixed capacitors.

Then to show some of the advantages and simulation alternatives of the proposed approach the 16 bus IEEE system was studied with the following considerations:

- $\quad$ Three load level were considered with the load duration data $(\mathrm{T}=$ one year) for the system presented in Table 4.

Table 3. Results for the four cases studied on the 16 bus IEEE system, case 1.

\begin{tabular}{|c|c|c|c|c|c|}
\hline \multicolumn{1}{|c|}{ Main items } & $\begin{array}{c}\text { Original } \\
\text { configuration }\end{array}$ & Case a & Case b & Case c & Case d \\
\hline Switches status alternated & - & $\{15,19\},\{21,17\}$ & - & $\{15,19\},\{21,17\}$ & $\{15,19\},\{21,17\}$ \\
\hline Maximum bus voltage & 1 & 1 & 1 & 1 & 1 \\
\hline Minimum bus voltage & 0.96927 & 0.971575 & 0.97132 & 0.97362 & 0.97362 \\
\hline Capacitors added [Kvar]: & & - & 1800 & 1800 & 1800 \\
\hline Bus 4 & - & - & 1800 & 0 & 1800 \\
\hline Bus 8 & - & 0.4691 & 0.4971 & 0.4552 & 0.4543 \\
\hline Bus 13 & - & 8.81 & 3.37 & 11.51 & 11.69 \\
\hline Total power loss [MW] & 0.5144 & & & & 900 \\
\hline Power loss reduction [\%] & - & & & & \\
\hline
\end{tabular}


Table 4. Load duration data. Case 2.

\begin{tabular}{|l|c|c|c|}
\hline & level 0 & level 1 & level 2 \\
\hline Load level (p.u.) & 1.1 & 0.6 & 0.3 \\
\hline Time interval (hours) & 1000 & 6760 & 1000 \\
\hline
\end{tabular}

- Voltage and current constraints were considered: Vmax $=1.1$ pu., Vmin $=0.9$ pu., Imin $=0.18$ pu.

- Instead of minimizing only power losses, the costs of capacitor and power-energy losses were considered too. The cost constants assumed for this problem according to equation (2), (3) are the following: $\mathrm{Kp}=300 \mathrm{US} \$$ / $\mathrm{kW} /$ year, Ke=0.1 US $\$ / \mathrm{kWh}$ and $\mathrm{Kc}=5 \mathrm{US} \$ / \mathrm{kVAr}$.

- $\quad$ The same switched and capacitors from the case 1 were considered, but now they can be located in any bus of the system.
Under these conditions the same four cases were analyzed. A costs comparison results are presented in Table 5 and the detail for the case $d$ is summarized in Table 6 .

From Table 5 it can be observed that the best solution corresponded to case d), with both feeder reconfiguration and capacitor setting are taken into account simultaneously.

\section{3 bus test system}

To analyze a large-scale distribution system a quite efficient string representation model was developed and a balanced distribution system modeling was employed, with comprehensive modeling of diverse components such as distribution lines, core losses in transformers, loads represented by diverse voltage dependent models and fixed or switched capacitors.

Table 5. Costs comparison for a 16 bus IEEE system, case 2.

\begin{tabular}{|l|c|c|c|c|c|}
\hline \multicolumn{1}{|c|}{ Main items } & Initial configuration & Case a & Case b & Case c & Case d \\
\hline Max total power loss [MW] & 0.6316 & 0.5988 & 0.5764 & 0.5574 & 0.5513 \\
\hline Total Cost loss [US\$] & 388427 & 377669 & 353230 & 354591 & 345352 \\
\hline Cost loss reduction [\%] & - & 2.8 & 9.1 & 8.7 & 11.1 \\
\hline
\end{tabular}

Table 6. Final results for 16 bus IEEE system, case 2.

Considering both capacitor addition and reconfiguration simultaneously.

\begin{tabular}{|l|c|c|c|}
\hline \multicolumn{1}{|c|}{ Main items } & Load level 0 & Load level 1 & Level 2 \\
\hline Switches status alternated & $\{17,21\}\{19,15\}$ & $\{17,21\}\{19,15\}$ & $\{14,26\}\{17,21\}\{19,15\}$ \\
\hline Maximum bus voltage & 1.000 & 1.000 & 1.002 \\
\hline Minimum bus voltage & 0.972 & 0.988 & 0.998 \\
\hline Capacitors added [Kvar] & & & 0 \\
\hline Bus 8 & 1800 & 0 & 0 \\
\hline Bus 7 & 1500 & 300 & 0 \\
\hline Bus 9 & 1200 & 0 & 0.0759 \\
\hline Total power loss [MW] & 0.5513 & 0.1700 & 0 \\
\hline
\end{tabular}

Table 7. Cost comparison for a practical 733-bus distribution system.

\begin{tabular}{|l|c|c|c|c|}
\hline & $\begin{array}{c}\text { Initial } \\
\text { configuration }\end{array}$ & $\begin{array}{c}\text { Only capacitor } \\
\text { placement }\end{array}$ & $\begin{array}{c}\text { Only feeder } \\
\text { reconfiguration }\end{array}$ & $\begin{array}{c}\text { Both capacitor placement and } \\
\text { reconfiguration simultaneously }\end{array}$ \\
\hline Max. power loss [KW] & 737 & 677 & 654 & 601 \\
\hline Total loss cost [US\$] & 100011 & 97334 & 89141 & 88866 \\
\hline Loss cost reduction [\%] & - & $2.7 \%$ & $10.9 \%$ & $11.2 \%$ \\
\hline
\end{tabular}


The method has been applied to a practical distribution system. It is a three-phase balance network, $13.8 \mathrm{kV}$, with 733 buses, 118 switches and 754 laterals.

Time variation of load is also involved, using annual load duration data, Table 8. Details of the data of this example system can be found in [26].

Table 8. Annual load duration data for 733 buses system.

\begin{tabular}{|l|c|c|c|c|}
\hline & level 0 & level 1 & level 2 & level 3 \\
\hline Load level (p.u.) & 1.03 & 0.894 & 0.771 & 0.589 \\
\hline Time interval (hrs.) & 2160 & 2160 & 2160 & 2160 \\
\hline
\end{tabular}

Voltage and current constraints were considered: $\mathrm{V} \max =1.15$ pu., $V \min =0.85$ pu., $\operatorname{Imin}=0.18$ pu.

A variable switched capacitor bank with four labels 150 , 300, 450, $600 \mathrm{kVAr}$ was assumed and a maximum of 4 new capacitor is considered. The capacitors cost function is given in equation (6)

$$
\mathrm{C}(\mathrm{Q})=810 \mathrm{US} \$+1.5 \mathrm{US} \$ / \operatorname{KvAr}(\mathrm{Q})
$$

Instead of minimizing only power losses, energy and peak load loss reduction, and capacitor cost are considered in the cost function. The cost constants assumed for this problem according to equation (2), (3) are the following: $\mathrm{Kp}=0,01938 \mathrm{US} \$ / \mathrm{kWh}, \mathrm{Ke}=9.1 \mathrm{US} \$ / \mathrm{kW} /$ year. Table 9 summarize the genetics parameters.

Test results confirm that the proposed approach can efficiently search the optimal or near-optimal solution for energy and power loss cost minimization considering feeder reconfiguration and capacitor placement.

Table 9. Genetics parameters for 733 buses test system.

\begin{tabular}{|l|c|}
\hline \multicolumn{1}{|c|}{ Genetic Parameter } & Setting value \\
\hline Initial population & 1000 \\
\hline Evolution population & 400 \\
\hline Maximum iterations & 4000 \\
\hline Switch mutation rate $(\%)$ & 0.005 \\
\hline Capacitor mutation rate (\%) & 0.001 \\
\hline Crossover rate $(\%)$ & 20 \\
\hline Switch crossover point $(\%)$ & 20 \\
\hline Fixed capacitor crossover point & 20 \\
\hline Capacitor placement crossover point $(\%)$ & 20 \\
\hline Capacitor size crossover point & 20 \\
\hline Penalty voltage factor (US\$/V) & 15000 \\
\hline Penalty current factor $(\mathrm{US} \$ \mathrm{~V})$ & 15000 \\
\hline
\end{tabular}

In addition, it can be seen from Table 7 that simultaneously taking into account both feeder reconfiguration and capacitor placement is more effective than using only one technique. The genetic algorithm performance in this case is shows in Figure 5.

\section{Total Lost Cost [US\$]}

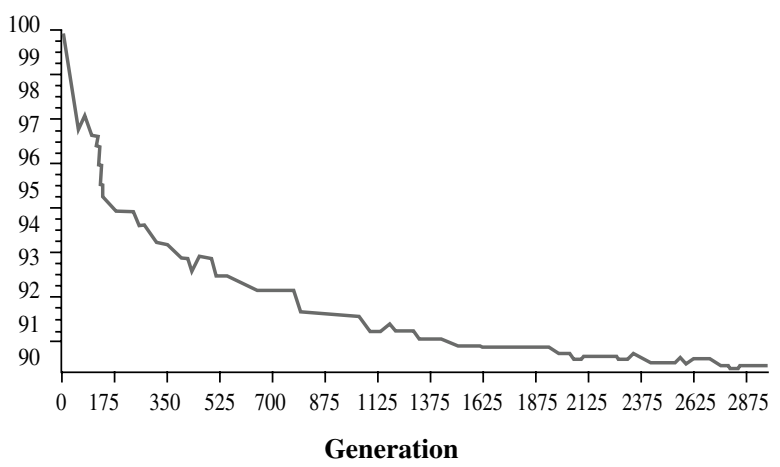

Figure 5. Genetic algorithm performance for a 733 buses test system.

\section{CONCLUSIONS}

In this paper a genetic algorithm (GA) is proposed for loss cost minimum optimization in distribution systems. The approach has been tested in many networks and the test results lead to the following conclusions:

- Taken into account both capacitor setting and feeder reconfiguration simultaneously can generate around $10 \%$ more energy-power losses reduction than considering them separately.

- An efficient coding system was developed for applying GA to the target problem; it handles possible generation of strings with violation of operational constraints, so that the proposed approach has a high efficiency in power-energy cost loss reduction.

- As size of the network and the load levels considered increase, the simultaneous solution requires more computational time than the separately solution (only reconfiguration or only capacitor setting).

- A detailed distribution network modeling is employed, it include loads represented by diverse voltage dependent models, load duration curve, fixed and switched capacitor, sectionalising and tie switches, transformer losses, fixed and variable capacitors costs. For this reason the result presented in this paper shown that the proposed approach has better response than other methods and is suitable for application to large-scale practical distribution systems. 


\section{REFERENCES}

[1] J.J. Grainger and S.H. Lee. "Capacity release by shunt capacitor placement on distribution feeders: a new voltage-dependent model". IEEE Trans. Power App. Syst. Vol. PAS-101, Issue 5, pp. 1236-1244. May 1982.

[2] M.E. Baran and F.F. Wu. "Optimal sizing of capacitors placed on a radial distribution system". IEEE Trans. Power Delivery. Vol. 4 No 1, pp. 735743. January 1989.

[3] H.D. Chiang, J.C. Wang, O. Cockings and H.D. Shin. "Optimal capacitor placement in distribution systems. Part I: A new formulation and the overall problem". IEEE Trans. Power Delivery. Vol. 5 $\mathrm{N}^{\circ}$ 2, pp. 634-642. April 1990.

[4] S. Sundhararajan and A. Pahwa. "Optimal selection of capacitors for radial distributions systems using a genetic algorithm". IEEE Trans. Power System. Vol. 9 No 3, pp. 1499-1507. August 1994.

[5] Y.C. Huang, H.T. Yang and C.L. Huang. "Solving the capacitor placement problem in a radial distribution system using tabu search approach". IEEE Trans. Power System. Vol. 11 N $^{\circ}$ 4, pp. 18681873. November 1996.

[6] L.L. Lai and J.T. Ma. "Application of evolutionary programming to reactive power planning-comparison with nonlinear programming approach". IEEE Trans. Power System. Vol. 12 N$^{\circ}$ 1, pp. 198-204. 1997.

[7] K.Y. Lee and F.F. Yang. "Optimal reactive power planning using evolutionary algorithms: a comparative study for evolutionary programming, evolutionary strategy, genetic algorithm and linear programming". IEEE Trans. Power System. Vol. 13 $\mathrm{N}^{\circ}$ 1, pp. 101-108. 1998.

[8] G. Levitin, A. Kalyuzhny, A. Shenkman and M. Chertkov. "Optimal capacitor allocation in distribution systems using a genetic algorithm and a fast energy loss computation technique". IEEE Trans. Power Delivery. Vol. 15 N$^{\circ}$ 2, pp. 623-628. April 2000.

[9] R.A. Gallego, A.J. Monticelli and R. Romero. "Optimal capacitor placement in radial distribution networks". IEEE Trans. Power System. Vol. 16 No 4, pp. 630-637. November 2001.

[10] M.A.S. Masoum, A. Jafarian, M. Ladjevardi, E.F. Fuchs and W.M. Grady. "Fuzzy approach for optimal placement and sizing of capacitor banks in the presence of harmonics". IEEE Trans. Power Delivery. Vol. 19, pp. 822-829. April 2004.

[11] J.P. Chiou, C.F. Chang and C.T. Su. "Ant direction hybrid differential evolution for solving large capacitor placement problems". IEEE Trans. Power
System. Vol. 19 N$^{\circ}$ 4, pp. 1794-1800. November 2004.

[12] M.R. Haghifam and O.P. Malik. "Genetic algorithm-based approach for fixed and switchable capacitors placement in distribution systems with uncertainty and time varying loads". IETGeneration, Transmission and Distribution. Vol. 1, Issue 2, pp. 244-252. March 2007.

[13] I.C. da Silva, S. Carneiro, E.J. de Oliveira, J. de Souza Costa, J.L.R. Pereira and P.A.N. Garcia. "A Heuristic Constructive Algorithm for Capacitor Placement on Distribution Systems". IEEE Trans. Power System. Vol. 23 No 4, pp. 1619-1626. November 2008.

[14] A. Merlin and H. Back. "Search for a minimal loss operating spanning tree configuration for an urban power distribution system". Proc. of the 5th Power System Conference (PSCC), pp. 1-18. Cambridge. 1975.

[15] S. Civanlar, J.J. Grainger, H. Yin and S.S.H. Lee. "Distribution feeder reconfiguration for loss reduction". IEE Trans. Power Delivery. Vol. $3 \mathrm{~N}^{\circ} 3$, pp. 1217-1222. July 1988.

[16] D. Shirmohammadi and H.W. Hong. "Reconfiguration of electric distribution networks for resistive line losses reduction”. IEEE Trans. on Power Delivery. Vol. $4 \mathrm{~N}^{\circ}$ 4. April 1989.

[17] K. Nara, A. Shiose, M. Kitagawoa and T. Ishihara. "Implementation of genetic algorithm for distribution system loss minimum reconfiguration". IEEE Trans. Power System. Vol. 7 № 3, pp. 1044-1051. August 1992.

[18] H.C. Cheng and C.C. Kou. "Network reconfiguration in distribution systems using simulated annealing". Electric Power System Research. Vol. 29, Issue 3, pp. 227-238. 1994.

[19] G.P. Peponis, M.P. Papadopoulos and N.D. Hatziargyriou. "Distribution network reconfiguration to minimize resistive line losses". IEEE Trans. Power Delivery. Vol. 10 No 3, pp. 1338-1342. July 1995.

[20] H. Rudnick, I. Harnisch and R. Sanhueza. "Reconfiguration of electric distribution systems". Revista de la Facultad de Ingeniería-Universidad de Tarapacá. Vol. 4. Arica, Chile. 1997.

[21] Y.T. Hsiao and C.Y. Chien. "Multiobjective optimal feeder reconfiguration". IEE Proc. Gener. Transm. Distrib. Vol. 148 N$^{\circ}$ 4, pp. 333-338. July 2001.

[22] J.P. Chiou, C.F. Chang and C.T. Su. "Variable scaling hybrid differential evolution for solving network reconfiguration of distribution systems". 
IEEE Trans. Power System. Vol. 20 N$^{\circ} 2$, pp. 668674. May 2005.

[23] E.M. Carreno, R. Romero and A. Padilha. "An Efficient Codification to Solve Distribution Network Reconfiguration for Loss Reduction Problem”. IEEE Trans. Power System. Vol. 23 $\mathrm{N}^{\circ}$ 4, pp. 1542-1551. November 2008.

[24] D. Jiang and R. Baldick. "Optimal electric distribution system switch reconfiguration and capacitor control”. IEEE Trans. Power System. Vol. 11 No $^{\circ}$, pp. 890-897. May 1996.

[25] C.T. Su and C.S. Lee. "Feeder reconfiguration and capacitor setting for loss reduction of distribution systems". Electric Power System Research. Vol. 58 $\mathrm{N}^{\circ}$ 2, pp. 97-102. 2001.

[26] R. Olivares. "Reconfiguración y localización óptima de condensadores en redes de distribución". Tesis para optar al título de Ingeniero Eléctrico. Departamento de Electrónica. Universidad de Tarapacá. Arica, Chile. 2001.

[27] Z. Rong, P. Xiyuan, H. Jinliang and S. Xinfu. "Reconfiguration and capacitor placement for loss reduction of distribution system”. TENCON ' 02
Proceedings. 2002 IEEE Region 10 Conference on Computers, Communications, Control and Power Engineering. Vol. 3, pp. 1945-1949. October 28-31, 2002.

[28] M. Kalantar, Rahman Dashti and Reza Dashti. "Combination of Network Reconfiguration and Capacitor Placement for Loss Reduction in Distribution System with Based Genetic Algorithm". In Proc. $41^{\text {st }}$ International Universities Power Engineering Conference, UPEC2006. Vol. 1, pp. 308-312. September 6-8, 2006.

[29] Z. Dong, F. Zhengcai, Y. Du and Z. Liuchun. "Capacitor switching and network reconfiguration for loss reduction in distribution system". IEEE Power Engineering Society General Meeting, pp. 1-6. Montreal, Canada. December 2006.

[30] D. Zhang, Z. Fu and L. Zhang. "Joint Optimization for Power Loss Reduction in Distribution Systems". IEEE Trans. Power System. Vol. 23 No 1, pp. 161169. 2008.

[31] Chung-Fu Chang. "Reconfiguration and Capacitor Placement for Loss Reduction of Distribution Systems by Ant Colony Search Algorithm". IEEE Trans. Power System. Vol. 23 No 4, pp. 161-169. 2008. 